\title{
Microwave Synthesis, Characterization, and Photoluminescence Properties of Nanocrystalline Zirconia
}

\author{
A. K. Singh ${ }^{1}$ and Umesh T. Nakate ${ }^{2}$ \\ ${ }^{1}$ DRDO Center for Piezoceramics and Devices, ARDE, Pashan, Pune 411021, India \\ ${ }^{2}$ Nanomaterials and Sensors Laboratory, Defence Institute of Advanced Technology (DU), \\ Girinagar, Pune 411025, India \\ Correspondence should be addressed to A. K. Singh; draksingh@hotmail.com
}

Received 30 August 2013; Accepted 24 October 2013; Published 21 January 2014

Academic Editors: P. Li, E. Poirier, and H. Yahiro

Copyright ( 2014 A. K. Singh and U. T. Nakate. This is an open access article distributed under the Creative Commons Attribution License, which permits unrestricted use, distribution, and reproduction in any medium, provided the original work is properly cited.

\begin{abstract}
We report synthesis of $\mathrm{ZrO}_{2}$ nanoparticles (NPs) using microwave assisted chemical method at $80^{\circ} \mathrm{C}$ temperature. Synthesized $\mathrm{ZrO}_{2}$ NPs were calcinated at $400^{\circ} \mathrm{C}$ under air atmosphere and characterized using FTIR, XRD, SEM, TEM, BET, and EDS for their formation, structure, morphology, size, and elemental composition. XRD results revealed the formation of mixed phase monoclinic and tetragonal $\mathrm{ZrO}_{2}$ phases having crystallite size of the order $8.8 \mathrm{~nm}$ from most intense XRD peak as obtained using Scherrer formula. Electron microscope analysis shows that the NPs were less than $10 \mathrm{~nm}$ and highly uniform in size having spherical morphology. BET surface area of $\mathrm{ZrO}_{2} \mathrm{NPs}$ was found to be $65.85 \mathrm{~m}^{2} / \mathrm{g}$ with corresponding particle size of $16 \mathrm{~nm}$. The band gap of synthesized NPs was found to be $2.49 \mathrm{eV}$ and PL spectra of $\mathrm{ZrO}_{2}$ synthesized NPs showed strong peak at $414 \mathrm{~nm}$, which corresponds to near band edge emission (UV emission) and a relatively weak peak at 475 and $562 \mathrm{~nm}$.
\end{abstract}

\section{Introduction}

$\mathrm{ZrO}_{2}$ (zirconia) is a material of great technological importance, having good natural color, high strength, high toughness, high chemical stability, excellent corrosion, and chemical and microbial resistance $[1,2] . \mathrm{ZrO}_{2}$ is a wide band gap Ptype semiconductor that exhibits abundant oxygen vacancies on its surface. The high ion exchange capacity and redox activities make it useful in many catalytic processes as a catalyst [3]. $\mathrm{ZrO}_{2}$ is also an important dielectric material that is being investigated for potential application as an insulator in transistors in future nanoelectric devices [4]. Garcia et al. [5] have highlighted its potential to replace $\mathrm{SiO}_{2}$ in advanced metal oxide semiconductor (MOS) devices and in optical applications.

$\mathrm{ZrO}_{2}$ has three well-defined crystal structures/phases, that is, cubic $\left(\mathrm{c}-\mathrm{ZrO}_{2}\right)$, tetragonal $\left(\mathrm{t}-\mathrm{ZrO}_{2}\right)$, and monoclinic $\left(\mathrm{m}-\mathrm{ZrO}_{2}\right)$, under normal atmosphere and at different temperatures $[6,7]$. Generally, $\mathrm{m}-\mathrm{ZrO}_{2}$ phase is thermodynamically stable up to $1100^{\circ} \mathrm{C}, \mathrm{t}-\mathrm{ZrO}_{2}$ phase exists in the temperature range of $1100-2370^{\circ} \mathrm{C}$, and the cubic phase is found above $2370^{\circ} \mathrm{C}[8]$. There are contradictory reports on the existence of various phases under different conditions of temperatures. Recently, existence of $\mathrm{t}-\mathrm{ZrO}_{2}$ at low temperature has been reported by many researchers [9-11]. Ciuparu et al. [9] have reported the initial existence of amorphous phase, and after heating above $750^{\circ} \mathrm{C}$, t-phase formation has been observed, and transition from tetragonal to monoclinic has been observed after calcinations at $1200^{\circ} \mathrm{C}$. Shukla et al. [11] have observed nucleation of $\mathrm{t}-\mathrm{ZrO}_{2}$ phase from the amorphous phase at $400^{\circ} \mathrm{C}$, which becomes stable at $600^{\circ} \mathrm{C}$, and after calcination at $800^{\circ} \mathrm{C}$ complete tetragonal-to-monoclinic phase transformation has been reported.

$\mathrm{ZrO}_{2}$ has many interesting characteristics, such as superior mechanical characteristics, increased fracture toughness, hardness, strength, high thermal expansion coefficient, low thermal conductivity, superplastic deformation, phase stability, and good chemical resistance, which have resulted in a variety of industrial and engineering applications that include high durability coating, catalytic agents, medical prosthetics, cutting tools, synthetic jewels, high density grinding media, wear components, bearings, seals, valves, nose cones and 
tiles for space shuttles and missiles, turbines, and the most demanding aviation engines [12-17]. It also has the best performance as ceramic dental material. $\mathrm{ZrO}_{2}$ has found uses in solid oxide fuel cells [18] and in $\mathrm{NO}_{x}, \mathrm{O}_{2}$ gas sensors [19]. The fully stabilized $\mathrm{ZrO}_{2}$ is also well suited for high temperature energy conversion systems, due to its high oxygen ion transport capabilities and good long-term stability.

In spite of many unique characteristics, it has serious drawback for engineering application because it undergoes phase transformation with a change in volume at high temperatures, whereas, for optical and electronic applications, precise evaluation of its band gap is of significance since wide variation has been reported in its band gap $[5,9] . \mathrm{ZrO}_{2}$ is usually in the form of $\mathrm{m}-\mathrm{ZrO}_{2}$ at room temperature. Thus, the synthesis and room temperature stabilization methods of nano-t- $\mathrm{ZrO}_{2}$ are very important and of scientific significance with application prospects.

To prepare nano- $\mathrm{ZrO}_{2}$, several methods have been reported that include sol-gel, flame spray, combustion, glycothermal process, hydrothermal processing, and precipitation routes [7, 20-24]. In particular, a chemical solution method, which involves formation of a stable particle by a direct reaction between the atoms or reaction species, provides the most suitable way of synthesizing a sample of imperfection/defect free particles. The sol-gel method is one of the most common methods that have been used to synthesize nano- $\mathrm{ZrO}_{2}$. Many of these methods of nano- $\mathrm{ZrO}_{2}$ preparation use a synthetic template material, which is not economical and relatively more expensive. In the literature, there are few reports on the usage of microwave method for the synthesis of $\mathrm{ZrO}_{2}[10,25,26]$ which is the novel route of synthesis of metal oxide NPs, being clean, costeffective, energy efficient, eco-friendly, rapid and convenient method of heating, and results in higher yields in shorter reaction times [27]. Here, we report simple, low temperatures of synthesis of nanocrystalline $\mathrm{ZrO}_{2}$ NPs using microwave assisted method. To the best of our knowledge, the reaction temperature we used is the lowest used in the synthesis of $\mathrm{ZrO}_{2}$ NPs. The synthesized NPs of $\mathrm{ZrO}_{2}$ were investigated using FTIR, XRD, SEM-EDS, and TEM analysis.

\section{Experimental Details}

2.1. Synthesis. All chemicals used in the synthesis have been used as received from chemical suppliers without any further purification and processing. $50 \mathrm{~mL}$ of $0.1 \mathrm{M}$ zirconium oxychloride octahydrate solution was prepared and $15 \mathrm{~mL}$ $1 \mathrm{~N} \mathrm{NaOH}$ solution was added dropwise in given solution with continuous stirring, after precipitation precursor solution was kept in microwave oven for $12 \mathrm{~min}$ with power $420 \mathrm{~W}$ and temperature $80^{\circ} \mathrm{C}$ using RAGA'S microwave system. Microwave used for this experiment was of power range of $140 \mathrm{~W}$ to $700 \mathrm{~W}$. Obtained precipitate was filtered, washed 23 times with DI water $(18.2 \mathrm{M} \Omega \cdot \mathrm{cm}$ resistivity) and then dried at temperature $150^{\circ} \mathrm{C}$ for several hours. Dried powder was crushed and calcinated in air atmosphere at $400^{\circ} \mathrm{C}$ for 2 hours and obtained sample was characterized.

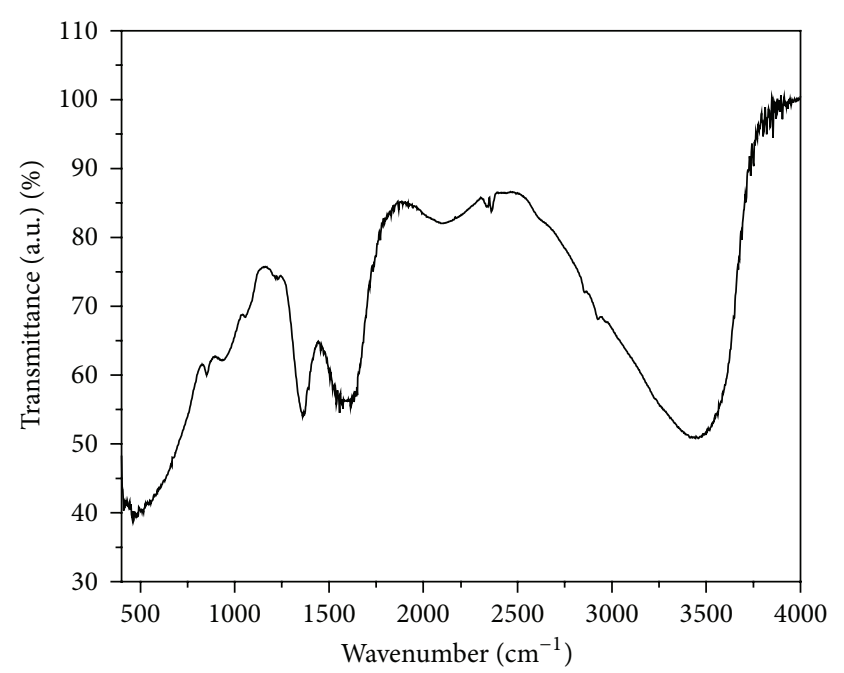

FIGURE 1: FTIR spectra of $\mathrm{ZrO}_{2}$ of NPs in the $400-4000 \mathrm{~cm}^{-1}$ region.

2.2. Characterization. The prepared annealed samples were characterized for their formation, structure, morphology, and elemental composition using Fourier transform infrared (FTIR) spectroscopy, X-ray diffraction analysis (XRD), scanning electron micrograph (SEM), transmission electron micrograph (TEM), energy dispersive spectrometer (EDS), Brunauer, Emmett and Teller (BET), and UV-Vis spectroscopy. FTIR of samples was performed using Shimadzu Affinity-1 FTIR spectrometer. Crystallographic study was carried out using Bruker AXS, Germany (Model D8 Advanced), diffractometer in the scanning range of $20-80^{\circ}(2 \theta)$ using $\mathrm{Cu} \mathrm{K} \alpha$ radiations of wavelength $1.5406 \AA$. JEOL ASM 6360A scanning electron microscope (SEM) was used to study the morphology and the elemental analysis. Transmission electron microscopy (TEM) of samples was carried out using FEI-Tecnai $G^{2} 20$. Measurement of BET surface area was carried out for nitrogen adsorption using a Micromeritics Ins., USA. UV-Vis spectroscopy of samples was done in the range of about $200-800 \mathrm{~nm}$ with the help of Ocean Optics HR4000 high-resolution spectrometer. Room temperature photoluminescence properties of NPs were studied using Perkin Elmer LS55 Luminescence Spectrometer in spectral range of 300-800 $\mathrm{nm}$ in the wavelength range of $270-320 \mathrm{~nm}$ as excitation source.

\section{Results and Discussion}

3.1. FTIR Analysis. In order to ascertain the molecular nature of the synthesized material, the FTIR spectrum of the $\mathrm{ZrO}_{2}$ sample was taken as shown in Figure 1. The spectrum of $\mathrm{ZrO}_{2}$ depends on the nature of the material, preparative procedures used, solid-state structure, and so forth. The observed strong FTIR absorption peak at about $470 \mathrm{~cm}^{-1}$ region is due to the $\mathrm{Zr}-\mathrm{O}$ vibration, which confirm the formation of $\mathrm{ZrO}_{2}$ structure [28], prominent peak of $1380 \mathrm{~cm}^{-1}$ region corresponds to $\mathrm{O}-\mathrm{H}$ bonding, peak in the region of $1553 \mathrm{~cm}^{-1}$ may be due to the adsorbed moisture and in the $3425-3495 \mathrm{~cm}^{-1}$ region is attributed to stretching of $\mathrm{O}-\mathrm{H}$ groups, characteristic of a highly hydrated compound [28]. 


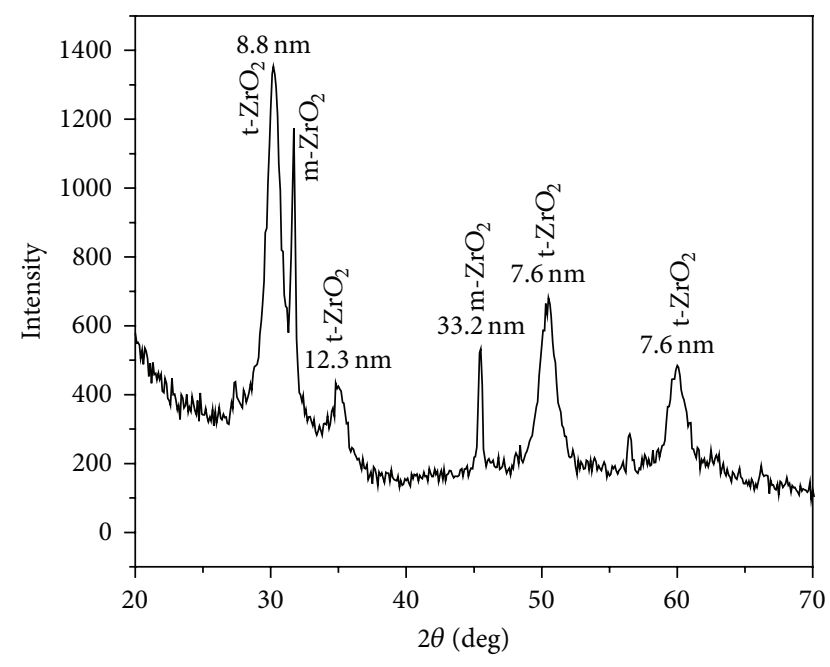

Figure 2: XRD pattern of $\mathrm{ZrO}_{2}$ NPs calcinated at $400^{\circ} \mathrm{C}$.

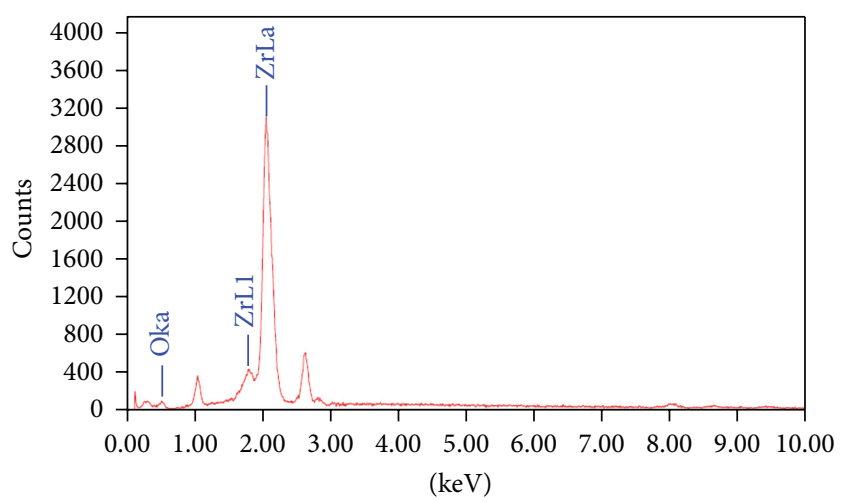

Figure 3: EDAX spectra of $\mathrm{ZrO}_{2}$ of NPs calcinated at $400^{\circ} \mathrm{C}$.

3.2. Crystallographic Analysis. To confirm the phase formation of $\mathrm{ZrO}_{2}, \mathrm{XRD}$ pattern of the sample was recorded after calcination in air atmosphere and is shown in Figure 2. The narrow line widths indicate high crystalline nature of the synthesized material. As reported by Shukla et al., [29] scan range of 27-32 degrees contained the strongest lines for monoclinic as well as tetragonal phases. Observed XRD peaks (Figure 2) for sample calcinated at $400^{\circ} \mathrm{C}$ indicate the formation of $\mathrm{t}-\mathrm{ZrO}_{2}$ and $\mathrm{m}-\mathrm{ZrO}_{2}$ mixed phases. Selection of calcination of sample at $400^{\circ} \mathrm{C}$ was based on earlier reports indicating that, in order to crystallize $\mathrm{ZrO}_{2}, \mathrm{OH}$ ion must be removed under thermal treatment and $\mathrm{ZrO}_{2}$ is crystallized at a temperature of about $400^{\circ} \mathrm{C}$ [23]. The distinguishing characteristic peaks for tetragonal occur at $2 \theta=30.2,34.5$, 50.2 , and 60.2 corresponding to the (101), (110), (200), and (211) reflections [JCPDS No. 70-1769] [30,31]. Stabilization of $\mathrm{t}$-phase at lower temperature is most likely due to low surface energy of the $\mathrm{t}$-phase relative to $\mathrm{m}$-phase. At $300^{\circ} \mathrm{C}$, zirconia has an amorphous structure and pure $\mathrm{ZrO}_{2}$ is crystallized at a temperature of about $400^{\circ} \mathrm{C}$ [23], but in our case we have observed mixed phase formation.

Mixed phase formation of $\mathrm{ZrO}_{2}$ is a common feature in zirconia synthesis and has been reported by many

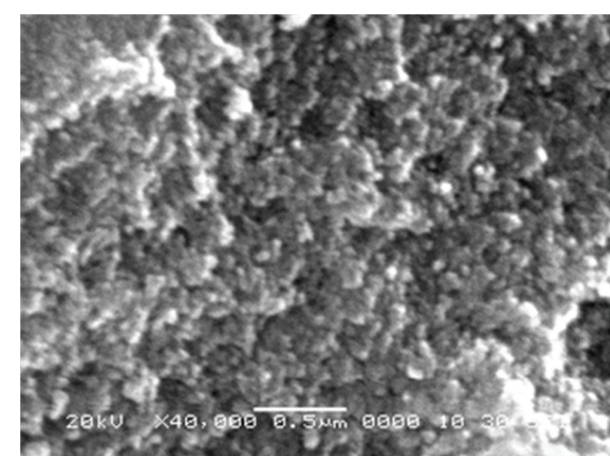

FIgURE 4: SEM micrographs of $\mathrm{ZrO}_{2}$ NPs.

authors [28]. Tyagi et al. [23] have reported $\mathrm{t}-\mathrm{ZrO}_{2}$ phase formation at $400^{\circ} \mathrm{C}$, and with increase in calcinations temperature they have reported $\mathrm{m}$ and $\mathrm{t}-\mathrm{ZrO}_{2}$. The occurrence of metastable tetragonal phase is attributed to the critical crystallite size effect as reported by Garvie [32]. Garvie experimentally showed the existence of a critical size of $30 \mathrm{~nm}$, below which the metastable t-phase is stable and above which the $\mathrm{m}$-phase is stable.

The crystallite size of NPs has been calculated by XRD line broadening of peak using Scherrer's formula [33]

$$
D=\frac{K \lambda}{\beta \operatorname{Cos} \theta},
$$

where $K$ is $0.9, \lambda$ is wave length of $\mathrm{X}$-ray source $(0.1540598 \mathrm{~nm}), \beta$ is full width at half maximum in radians, and $\theta$ is Bragg's diffraction angle. Crystallite sizes, calculated using Scherrer's formula (1), are indicated in Figure 2 corresponding to each peak and are the order of $8.8 \mathrm{~nm}$ from most intense XRD peak, whereas average size is about $14 \mathrm{~nm}$ which is in close agreement with the particle size of $\mathrm{ZrO}_{2}$ as obtained from BET surface area analysis as discussed.

3.3. Elemental and Morphological Analysis. The synthesis of $\mathrm{ZrO}_{2}$ NPs was confirmed by recording EDAX spectra and is depicted in Figure 3. Emission peaks, such as OKa, ZrL1, and $\mathrm{ZrLa}$ were observed in the EDAX spectrum confirmed the stoichiometry of synthesized NPs. It shows that $\mathrm{Zr}$ and $\mathrm{O}$ elements are present almost in stiochoimetric ratio.

Morphological investigations of $400^{\circ} \mathrm{C}$ air calcinated $\mathrm{ZrO}_{2}$ sample were carried out using SEM and TEM and are shown in Figures 4 and 5, respectively. The morphological characterization highlighted the importance of nanocrystalline $\mathrm{ZrO}_{2}$ preparation in maintaining the nanostructured phase. It is clear from Figure 4 that NPs are of uniform size. Observation of Figure 4 shows that $\mathrm{ZrO}_{2}$ particles are spherical in nature and size of the particles is in the $\mathrm{nm}$ regime, but size could not be finely resolved from SEM. For the purpose, TEM of sample has been shown in Figure 5. As can be seen from TEM micrographs of sample, some agglomeration has been observed due to different $\mathrm{t}$ - and $\mathrm{m}$ phases present in the sample. In spite of agglomeration of the NPs, it can be observed that the sizes of the particles are 


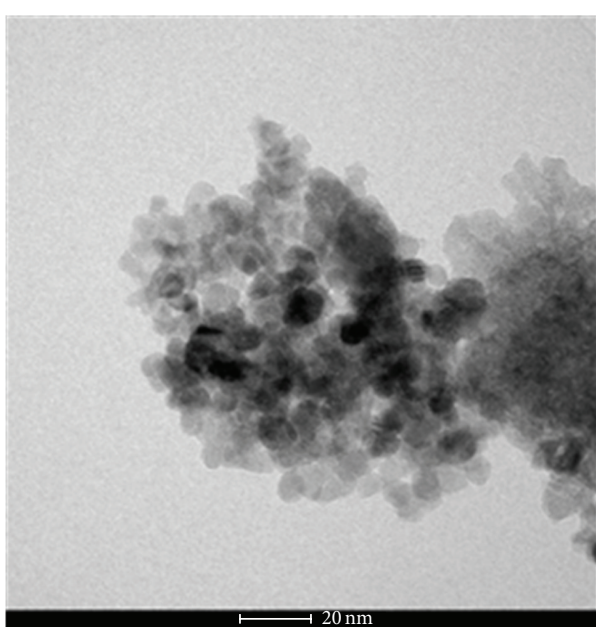

(a)

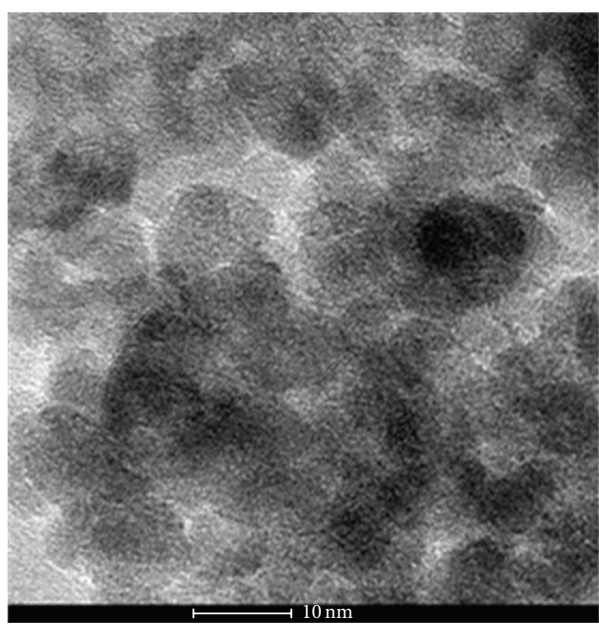

(c)

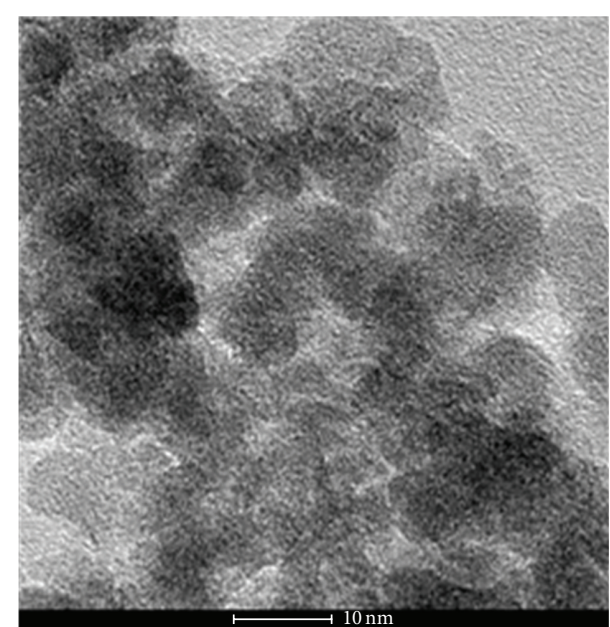

(b)

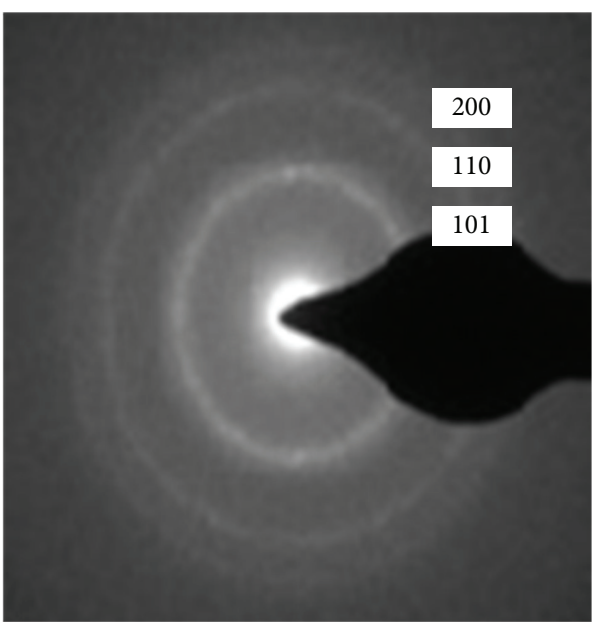

(d)

FIGURE 5: TEM micrographs of $\mathrm{ZrO}_{2}$ NPs at different magnifications (a)-(c) and electron diffraction pattern taken on a selected area of the sample (d).

of the order $10 \mathrm{~nm}$. The TEM results are also supporting the results of other analyses based on XRD and BET surface area calculations.

Figure 5(d) shows an electron diffraction pattern indicating well-defined quasicontinuous diffraction rings of the sample that calcined at $400^{\circ} \mathrm{C}$ for $2 \mathrm{~h}$. It is noticeable that the (101), (110), and (200) planes are clearly distinguished [34] as observed in XRD patterns.

3.4. BET Analysis. Surface area analysis was done by nitrogen absorption using BET surface analyzer. NPs size has been calculated from surface area assuming NPs to be of spherical shape, using the following equation [35]:

$$
d=\frac{6}{\rho S_{\mathrm{BET}}},
$$

where $\rho$ is the density of $\mathrm{ZrO}_{2}$ particles and $S_{\mathrm{BET}}$ is the BET surface area for powder sample calcinated at $400^{\circ} \mathrm{C}$; measured BET surface area has been found to be $65.85 \mathrm{~m}^{2} / \mathrm{g}$. Particle size of $\mathrm{ZrO}_{2}$ NPs was found to be $16 \mathrm{~nm}$ from (2) which is in agreement with the above discussion under the assumption used in the analysis.

3.5. Band Gap Analysis. Reduction in the nanoparticle size can cause change in the optical band gap of metal oxides through the narrowing of the valence and conduction bands [5]. The other important factors that can affect optical band gap are defect centers, mechanical stress, and changes in the crystallinity. Optical absorption spectra of NPs, as shown in Figure 6, have been studied without taking into account the reflection and transmission losses. Tauc's relation of the absorption coefficient $(\alpha)$ with the photon energy $(h \nu)$ has been used to determine the band gap energy of sample and is given by

$$
\alpha=\frac{\alpha_{0}\left(h v-E_{g}\right)}{h v}
$$




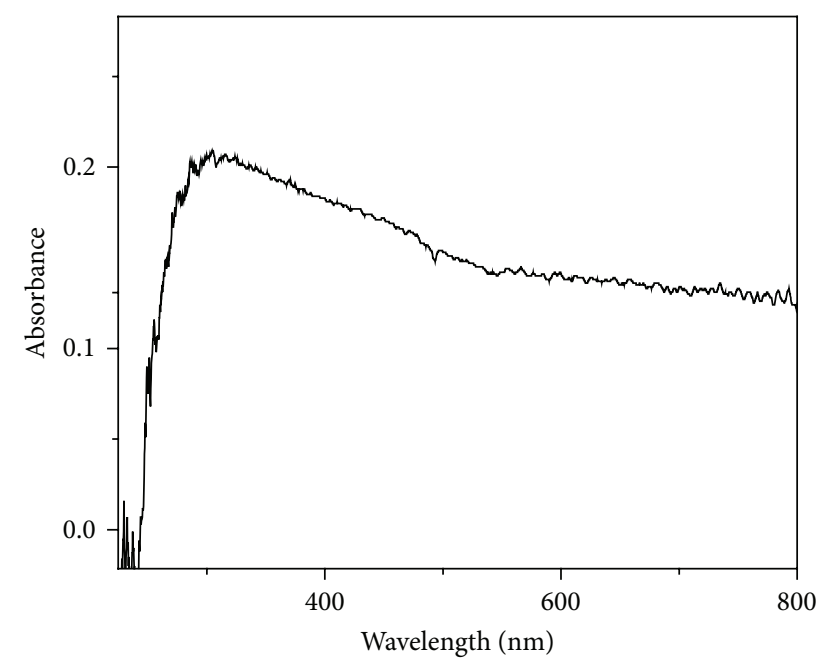

FIGURE 6: UV-Vis absorbance spectra of microwave synthesized $\mathrm{ZrO}_{2}$ sample calcinated at $400^{\circ} \mathrm{C}$.

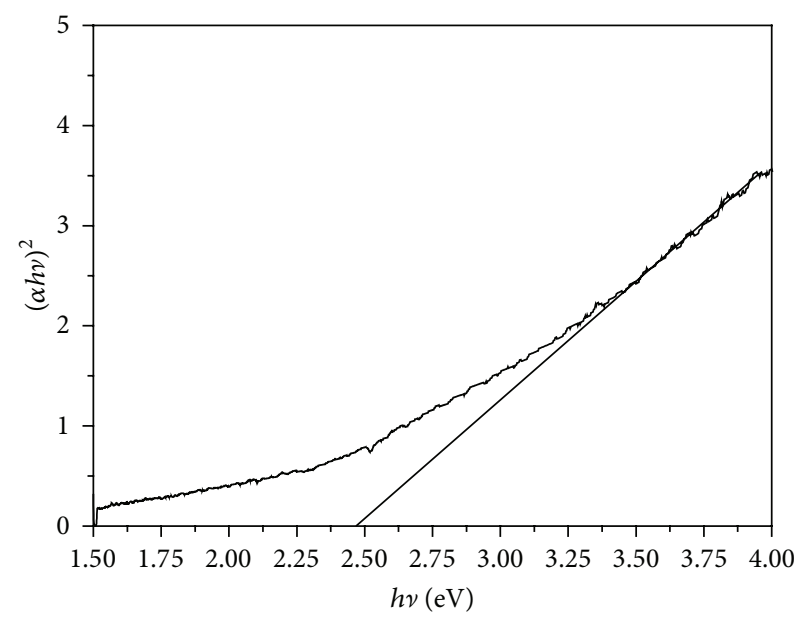

Figure 7: Plot of $(\alpha h v)^{2}$ versus $h v$ for $\mathrm{ZrO}_{2}$ sample calcinated at $400^{\circ} \mathrm{C}$.

where $\alpha$ is the absorption coefficient, $\alpha_{0}$ is the constant, $h \nu$ is the photon energy, and $E_{g}$ is the band gap energy of the material. The value of $n$ depends on the probability of transition; it takes values as $1 / 2,3 / 2,2$, and 3 for direct allowed, direct forbidden, indirect allowed, and indirect forbidden, respectively. The variation of $(\alpha h v)^{2}$ versus $h v$ is linear at the absorption edge which confirms that $\mathrm{ZrO}_{2}$ is semiconductor with direct band gap. The plot of $(\alpha h v)^{2}$ versus $h \nu$ is shown in Figure 7. Extrapolating the straight-line portion from higher absorption region of the plot $(\alpha h \nu)^{2}$ versus $h \nu$ to photon energy axis for zero absorption coefficient value gives the $E_{g}$ (Figure 8), giving a value of about $2.49 \mathrm{eV}$ [36]. In the literature, a wide variation has been reported in the band gap of $\mathrm{ZrO}_{2}$ which can be attributed to presence of the zirconia phase, defect state, and morphology.

3.6. Photoluminescence. Photoluminescence (PL) technique is suitable to determine the crystalline quality and presence

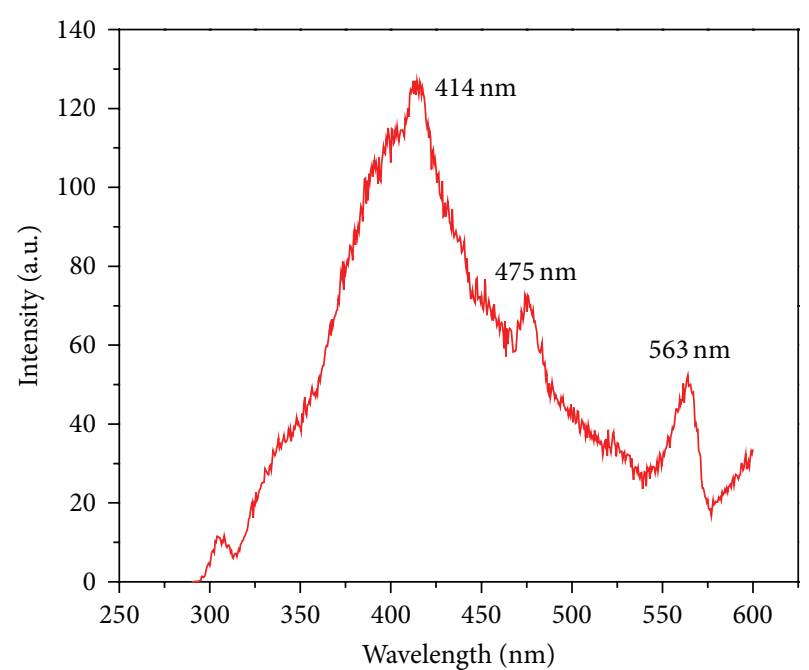

FIGURE 8: PL spectra of microwave synthesized $\mathrm{ZrO}_{2}$ sample excited at wavelength $270 \mathrm{~nm}$.

of impurities in the materials, as well as exciton fine structure. Figure 8 shows the room temperature photoluminescence spectra of $\mathrm{ZrO}_{2} \mathrm{NPs}$ excited at four different wavelengths, that is, $270,290,300$, and $320 \mathrm{~nm}$. Representative fluorescence spectrum with an excitation wavelength of $270 \mathrm{~nm}$ shown in Figure 8 exhibited three emission PL bands at around 414, 475 , and $563 \mathrm{~nm}$, with $414 \mathrm{~nm}$ being the prominent peak. Liang et al. [10] have also reported similar results for t$\mathrm{ZrO}_{2}$. As the fluorescence intensity somewhat varied with the excitation wavelength, the fluorescence band position and the band shape stayed nearly the same for these excitation wavelengths. This indicated that the fluorescence involved the same initial and final states in the excitation wavelengths ranging from 270 to $320 \mathrm{~nm}$. It can be accounted for by fast relaxation from the final state arrived at by photo-excitation to those states from which the fluorescence started [37]. The spectrum features a broad fluorescence band cantered at $414 \mathrm{~nm}$. Although the detailed PL mechanism for the nano$\mathrm{ZrO}_{2}$ is still under research, we could ascribe the emissions that appear at short wavelength excitation to the near bandedge transitions. The PL peak at $414 \mathrm{~nm}$ is attributed to $\mathrm{Zr}$ vacancies which is one of the intense peaks considered to be due of band edge emission due to the free-exciton recombination [38]. In the case of the emission at 475 and $563 \mathrm{~nm}$, it should be due to the involvement of mid-gap trap states, such as surface defects and oxygen vacancies. The weak green emission also implies that there are surface defects in $\mathrm{ZrO}_{2}$ NPs. Large amounts of surface defects exist on the as-synthesized nano- $\mathrm{ZrO}_{2}$ particles because of their high surface area. The broad band and the substantial red shift of the band maximum compared to the band gap of the bulk material $(5.6 \mathrm{eV})$ strongly indicate that the fluorescence involves extrinsic states. Because the particle size distribution is very narrow, the broad fluorescence band seems to be mostly caused by the small particle size leading to an inhomogeneous broadening from a distribution of surface or defect states. 


\section{Conclusions}

$\mathrm{ZrO}_{2}$ NPs have been synthesized with the help of a simple microwave assisted chemical process at low temperature. The TEM analysis reveals that the size of the spherical NPs is in the range of $8-10 \mathrm{~nm}$. All analyses have consistently shown fairly uniform NPs with superfine size having mixed $\mathrm{t}-\mathrm{ZrO}_{2}$ and $\mathrm{m}-\mathrm{ZrO}_{2}$ phases. Band gap and PL of the synthesized sample were investigated and band gap of the synthesized $\mathrm{ZrO}_{2}$ sample was found to be $2.48 \mathrm{eV}$ from Tauc's relation from UV-Vis absorption spectroscopy. Room temperature PL study of synthesized sample showed three emission PL bands at around 414, 475, and $563 \mathrm{~nm}$, with $414 \mathrm{~nm}$ being the prominent peak when excited at $270 \mathrm{~nm}$.

\section{Conflict of Interests}

The authors declare that they have no conflict of interests regarding the publication of this paper.

\section{Acknowledgments}

The authors are thankful to Vice Chancellor, Defence Institute of Advanced Technology, Girinagar, Pune, India, and Director, ARDE, Pune, India for granting permission to publish this work. They are also thankful to Department of Physics, University of Pune, Pune, India, for TEM, SEM, EDS, and XRD of samples.

\section{References}

[1] A. Hirvonen, R. Nowak, Y. Yamamoto, T. Sekino, and K. Niihara, "Fabrication, structure, mechanical and thermal properties of zirconia-based ceramic nanocomposites," Journal of the European Ceramic Society, vol. 26, no. 8, pp. 1497-1505, 2006.

[2] J. C. Ray, D. Park, and W. Ahn, "Chemical synthesis of stabilized nanocrystaline zirconia powders," Journal of Industrial and Engineering Chemistry, vol. 12, no. 1, pp. 142-148, 2006.

[3] J. L. Gole, S. M. Prokes, J. D. Stout, O. J. Glembocki, and R. Yang, "Unique properties of selectively formed zirconia nanostructures," Advanced Materials, vol. 18, no. 5, pp. 664-667, 2006.

[4] G. Dutta, K. P. S. S. Hembram, G. M. Rao, and U. V. Waghmare, "Effects of $\mathrm{O}$ vacancies and $\mathrm{C}$ doping on dielectric properties of $\mathrm{ZrO}_{2}$ : a first-principles study," Applied Physics Letters, vol. 89, no. 20, Article ID 202904, 2006.

[5] J. C. Garcia, L. M. R. Scolfaro, A. T. Lino et al., "Structural, electronic, and optical properties of $\mathrm{ZrO}_{2}$ from ab initio calculations," Journal of Applied Physics, vol. 100, no. 10, Article ID 104103, 2006.

[6] D. He, Y. Ding, H. Luo, and C. Li, "Effects of zirconia phase on the synthesis of higher alcohols over zirconia and modified zirconia," Journal of Molecular Catalysis A, vol. 208, no. 1-2, pp. 267-271, 2004.

[7] S. Roy, "Nanocrystalline undoped tetragonal and cubic zirconia synthesized using poly-acrylamide as gel and matrix," Journal of Sol-Gel Science and Technology, vol. 44, no. 3, pp. 227-233, 2007.

[8] T. Chraska, A. H. King, and C. C. Berndt, "On the sizedependent phase transformation in nanoparticulate zirconia,"
Materials Science and Engineering A, vol. 286, no. 1, pp. 169-178, 2000.

[9] D. Ciuparu, A. Ensuque, G. Shafeev, and F. Bozon-Verduraz, "Synthesis and apparent bandgap of nanophase zirconia," Journal of Materials Science Letters, vol. 19, no. 11, pp. 931-933, 2000.

[10] J. Liang, Z. Deng, X. Jiang, F. Li, and Y. Li, "Photoluminescence of tetragonal $\mathrm{ZrO}_{2}$ nanoparticles synthesized by microwave irradiation," Inorganic Chemistry, vol. 41, no. 14, pp. 3602-3604, 2002.

[11] S. Shukla, S. Seal, R. Vij, S. Bandyopadhyay, and Z. Rahman, "Effect of nanocrystallite morphology on the metastable tetragonal phase stabilization in zirconia," Nano Letters, vol. 2, no. 9 , pp. 989-993, 2002.

[12] Q. Zhang, J. Shen, J. Wang, G. Wu, and L. Chen, "Sol-gel derived $\mathrm{ZrO}_{2}-\mathrm{SiO}_{2}$ highly reflective coatings," International Journal of Inorganic Materials, vol. 2, no. 4, pp. 319-323, 2000.

[13] P. K. Wright and A. G. Evans, "Mechanisms governing the performance of thermal barrier coating," Current Opinion in Solid State and Materials Science, vol. 4, pp. 25-30, 1999.

[14] C. Piconi and G. Maccauro, "Zirconia as a ceramic biomaterial," Biomaterials, vol. 20, no. 1, pp. 1-25, 1999.

[15] P. Salas, E. de la Rosa-Cruz, L. A. Diaz-Torres, V. M. Castaño, R. Meléndrez, and M. Barboza-Flores, "Monoclinic $\mathrm{ZrO}_{2}$ as a broad spectral response thermoluminescence UV dosemeter," Radiation Measurements, vol. 37, no. 2, pp. 187-190, 2003.

[16] L. Kumari, G. H. Du, W. Z. Li, R. S. Vennila, S. K. Saxena, and D. Z. Wang, "Synthesis, microstructure and optical characterization of zirconium oxide nanostructures," Ceramics International, vol. 35, no. 6, pp. 2401-2408, 2009.

[17] J. Karch, R. Birringer, and H. Gleiter, "Ceramics ductile at low temperature," Nature, vol. 330, no. 6148, pp. 556-558, 1987.

[18] S. Park, J. M. Vohs, and R. J. Gorte, "Direct oxidation of hydrocarbons in a solid-oxide fuel cell," Nature, vol. 404, no. 6775, pp. 265-267, 2000.

[19] E. C. Subbarao and H. S. Maiti, "Science and technology of zirconia," Advances in Ceramics, vol. 24, pp. 731-737, 1988.

[20] A. I. Y. Tok, F. Y. C. Boey, S. W. Du, and B. K. Wong, "Flame spray synthesis of $\mathrm{ZrO}_{2}$ nano-particles using liquid precursors," Materials Science and Engineering B, vol.130, no. 1-3, pp. 114-119, 2006.

[21] S. Shukla, S. Seal, R. Vij, and S. Bandyopadhyay, "Effect of HPC and water concentration on the evolution of size, aggregation and crystallization of sol-gel nano zirconia," Journal of Nanoparticle Research, vol. 4, no. 6, pp. 553-559, 2002.

[22] T. K. G. Lam, A. Opalinska, T. Chudoba et al., "Preparation and characterization of $\mathrm{ZrO}_{2}: \mathrm{Er}^{3+}, \mathrm{Yb}^{3+}$ nanoparticles using a high pressure assisted soft template," Advances in Natural Sciences: Nanoscience and Nanotechnology, vol. 1, no. 2, Article ID 025008, 5 pages, 2010.

[23] B. Tyagi, K. Sidhpuria, B. Shaik, and R. V. Jasra, "Synthesis of nanocrystalline zirconia using sol-gel and precipitation techniques," Industrial and Engineering Chemistry Research, vol. 45, no. 25, pp. 8643-8650, 2006.

[24] J. S. Kim, D. H. Lee, S. Kang, D. S. Bae, H. Y. Park, and M. K. Na, "Synthesis and microstructure of zirconia nanopowders by glycothermal processing," Transactions of Nonferrous Metals Society of China, vol. 19, no. 1, pp. s88-s91, 2009.

[25] K. P. S. S. Hembram and G. M. Rao, "Microwave synthesis of zirconia nanoparticles," Journal of Nanoscience and Nanotechnology, vol. 8, no. 8, pp. 4159-4162, 2008. 
[26] R. Dwivedi, A. Maurya, A. Verma, R. Prasad, and K. S. Bartwal, "Microwave assisted sol-gel synthesis of tetragonal zirconia nanoparticles," Journal of Alloys and Compounds, vol. 509, no. 24, pp. 6848-6851, 2011.

[27] A. K. Singh and U. T. Nakate, "Photocatalytic properties of microwave-synthesized $\mathrm{TiO}_{2}$ and $\mathrm{ZnO}$ nanoparticles using malachite green dye," Journal of Nanoparticles, vol. 2013, Article ID 310809, 7 pages, 2013.

[28] L. A. Pérez-Maqueda and E. Matijević, "Preparation and characterization of nanosized zirconium (hydrous) oxide particles," Journal of Materials Research, vol. 12, no. 12, pp. 3286-3292, 1997.

[29] S. Shukla, S. Seal, and R. Vanfleet, "Sol-gel synthesis and phase evolution behavior of sterically stabilized nanocrystalline zirconia," Journal of Sol-Gel Science and Technology, vol. 27, no. 2, pp. 119-136, 2003.

[30] F. Heshmatpour and R. B. Aghakhanpour, "Synthesis and characterization of superfine pure tetragonal nanocrystalline sulfated zirconia powder by a non-alkoxide sol-gel route," Advanced Powder Technology, vol. 23, no. 1, pp. 80-87, 2012.

[31] X. Xu and X. Wang, "Fine tuning of the sizes and phases of $\mathrm{ZrO}_{2}$ nanocrystals," Nano Research, vol. 2, no. 11, pp. 891-902, 2009.

[32] R. C. Garvie, "The occurrence of metastable tetragonal zirconia as a crystallite size effect," Journal of Physical Chemistry, vol. 69, no. 4, pp. 1238-1243, 1965.

[33] A. K. Singh, "Synthesis, characterization, electrical and sensing properties of ZnO nanoparticles," Advanced Powder Technology, vol. 21, no. 6, pp. 609-613, 2010.

[34] F. Kazemi, A. Saberi, S. Malek-Ahmadi, S. Sohrabi, H. R. Rezaie, and M. Tahriri, "A novel method for synthesis of metastable tetragonal zirconia nanopowders at low temperatures," Ceramics-Silikáty, vol. 55, no. 1, pp. 26-30, 2011.

[35] J. Wang, J. Polleux, J. Lim, and B. Dunn, "Pseudocapacitive contributions to electrochemical energy storage in $\mathrm{TiO}_{2}$ (anatase) nanoparticles," Journal of Physical Chemistry C, vol. 111, no. 40, pp. 14925-14931, 2007.

[36] M. Aguilar-Frutis, G. Reyna-Garcia, M. Garcia-Hipolito, J. Guzman-Mendoza, and C. Falcony, "Optical, structural, and electrical characteristics of high dielectric constant zirconium oxide thin films deposited by spray pyrolysis," Journal of Vacuum Science and Technology A, vol. 22, no. 4, pp. 1319-1325, 2004.

[37] M. Salavati-Niasari, M. Dadkhah, and F. Davar, "Pure cubic $\mathrm{ZrO}_{2}$ nanoparticles by thermolysis of a new precursor," Polyhedron, vol. 28, no. 14, pp. 3005-3009, 2009.

[38] A. K. Singh, V. Viswanath, and V. C. Janu, "Synthesis, effect of capping agents, structural, optical and photoluminescence properties of $\mathrm{ZnO}$ nanoparticles," Journal of Luminescence, vol. 129, no. 8, pp. 874-878, 2009. 

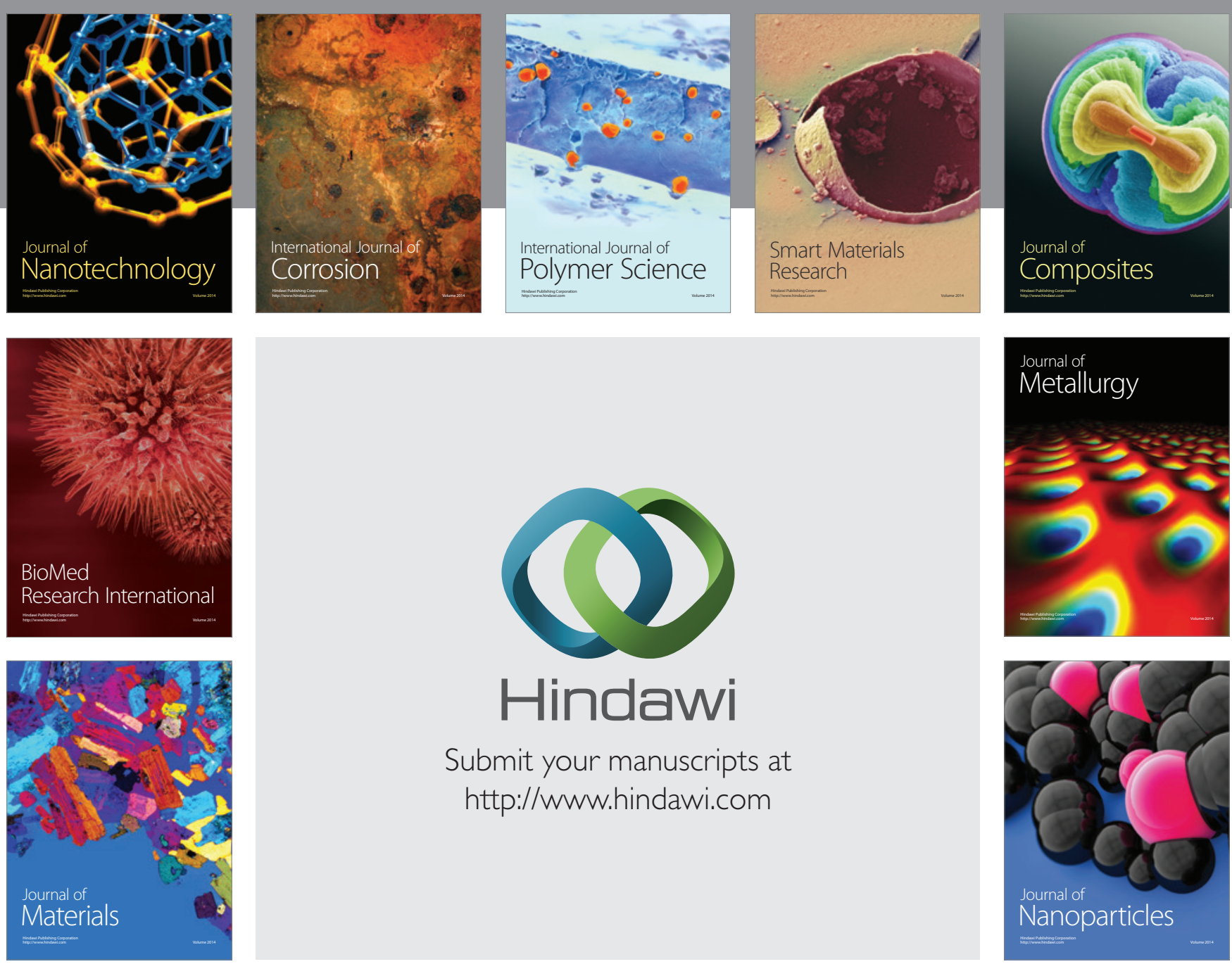

Submit your manuscripts at http://www.hindawi.com
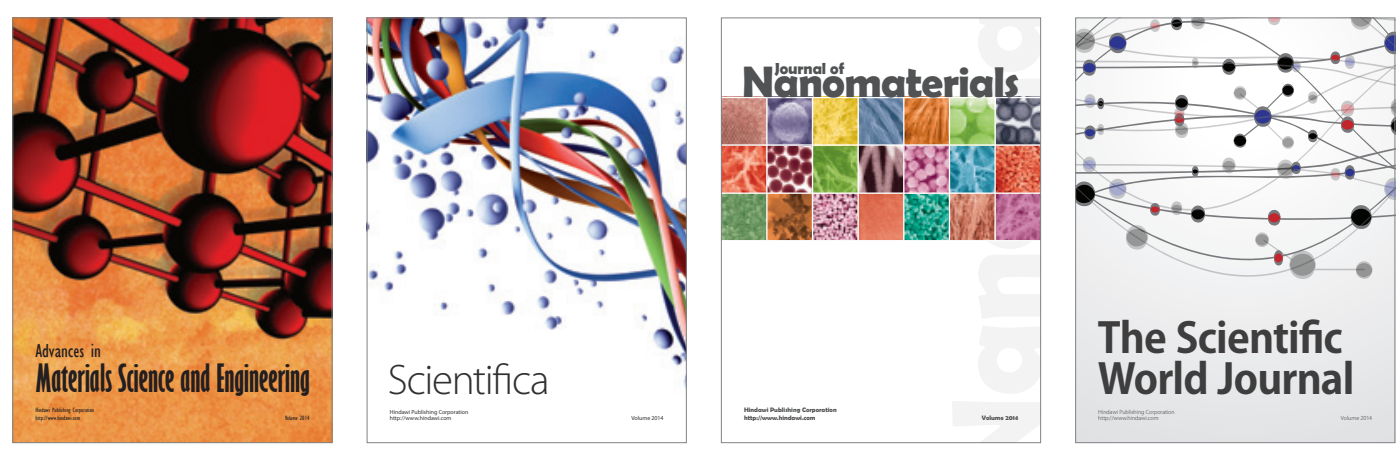

\section{The Scientific World Journal}
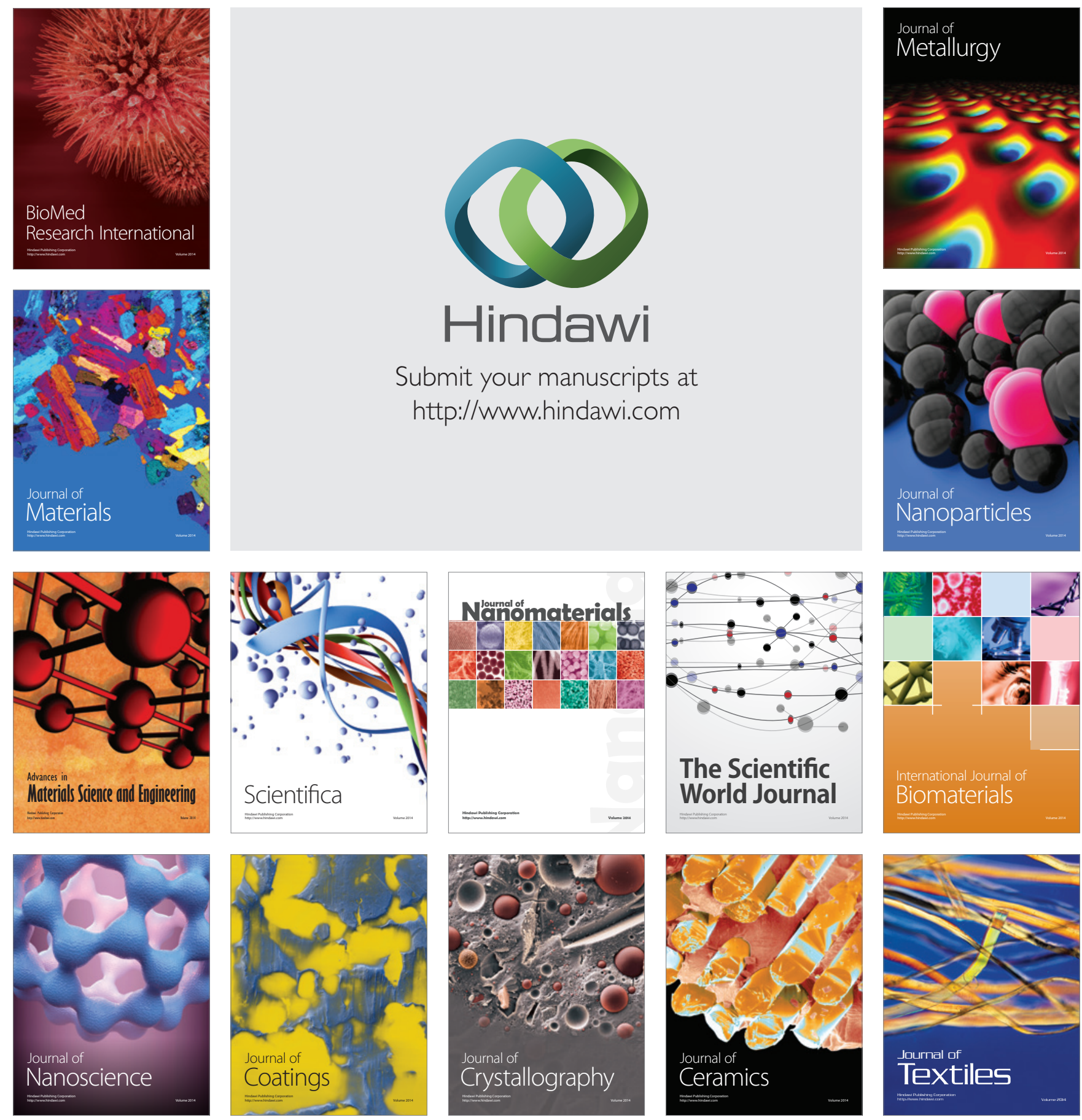